\title{
PELA PELE: HISTÓRIAS DE AFETIVIDADES, COMUNICAÇÃO E MEMÓRIA NA PELE EM NATAL/RN
}

\section{For the Skin: stories of affectivity, memory and communication in the skin in}

Natal / RN

\section{Para la piel: historias de la afectividad, memoria y comunicación en la piel en Natal / RN}

\author{
Maria Angela Pavan ${ }^{1}$ \\ Denise Leal L. Martins ${ }^{2}$
}

\section{Resumo}

Jack Daniel's, Salvador Dali e Jack Nicholson, Alex DeLarge do filme Laranja Mecânica e Night Elf do jogo virtual War of Craft. Todos esses elementos tem mais em comum do que o tocante a mídia visual e audiovisual, são as tatuagens dos entrevistados da pesquisa "Memória da pele e histórias de consumo: marcas e produtos tatuados no corpo" da UFRN, que resultou no vídeo-documentário "Pela Pele: Technicolor em gotas . Todos são potiguares (nascidos em Natal/RN) por nascimento ou por adoção e trazem no corpo o sinal do afeto com sua identificação. Este artigo pretende fazer uma reflexão do processo de construção do vídeo documentário e análise das entrevistas transcritas, com vistas ao entendimento identitário instaurado nas tatuagens. Iniciamos com uma abordagem teórica sobre as definições e conceituações de identidade em Hall (2000), Breton (2009) e Maffesoli (2000). Refletimos a partir de Canevacci (2008 2010) Appadurai (2004) os estudos dos fenômenos comunicação e cultura e de mediação sígnica do consumo por meio de suas marcas na vida afetiva das pessoas.

Palavras-chaves: tatuagem, consumo, comunicação, identidade e cultura.

\footnotetext{
${ }^{1}$ Professora do Departamento de Comunicação e da Pós Graduação em Estudos da Mídia da UFRN, vice coordenadora do grupo de estudos Pragma- Pragmática da Comunicação e Mídia: teorias, linguagens, indústrias culturais e cidadania da UFRN e Membro do Grupo de Estudos e Pesquisas sobre Linguagem e Narrativas da UNESP.

${ }^{2}$ Orientanda de IC da UFRN. Cursou Comunicação na UFRN e é membro do grupo de estudos PragmaPragmática da Comunicação e Mídia: teorias, linguagens, indústrias culturais e cidadania da UFRN CNPq.
} 
Pela pele: histórias de afetividades, comunicação e memória na pele em natal/rn

\section{Abstract}

Jack Daniel's, Jack Nicholson and Salvador Dali, Alex DeLarge from A Clockwork Orange Movie Night Elf and the virtual game of War Craft. All these elements have more in common than that respect visual and audiovisual media, are the tattoos of survey respondents "Memory skin and stories of consumer: brand and product names tattooed on the body" UFRN, which resulted in the documentary video "for Skin: Technicolor in drops. All are potiguares (born in Natal / RN) by birth or adoption and bring the body the sign of affection with their identification. This article aims to reflect the process of building the documentary video and analysis of the transcribed interviews, with a view to understanding identity established in tattoos. We start with a theoretical approach to the definitions and conceptualizations of identity in Hall (2000), Breton (2009) and Maffesoli (2000). We reflected from Canevacci (2008 - 2010) Appadurai (2004) studies the phenomena of culture and communication and mediation semiotic consumption through its brands in the emotional life of the people.

Keywords: Tattoo, Consumption, Communication, Culture and Identity.

\section{Resumen}

Jack Daniel's, Jack Nicholson y Salvador Dalí, Alex DeLarge de la película Clockwork Orange, Elf Noche del juego virtual de War Craft. Todos estos elementos tienen más en común de lo que los medios respeten visuales y audiovisuales, están los tatuajes de los encuestados "piel de memoria y las historias de los consumidores: tatuados los nombres de productos y marcas en el cuerpo" UFRN, lo que resultó en el video documental "Para la piel: Technicolor en gotas. Todos son potiguares (nacidos en Natal / RN) por nacimiento o adopción y llevar el cuerpo de la señal de afecto con su identificación. Este artículo trata de reflejar el proceso de construcción del video documental y el análisis de las entrevistas transcritas, con el fin de entender la identidad establecida en tatuajes. Comenzamos con una aproximación teórica a las definiciones y conceptualizaciones de identidad en el pabellón (2000), Breton (2009) y Maffesoli (2000). Reflexionamos desde Canevacci (2008 - 2010) Appadurai (2004) estudia los fenómenos de la cultura y la comunicación y el consumo de mediación semiótica a través de sus marcas en la vida emocional de las personas. 
Palabras-clave: tattoo, consumo, comunicación, cultura e identidad.

\section{INTRODUÇÃO}

Um terreno a desbravar: procurar pessoas em Natal que tivessem alguma tatuagem de marca ou produto de consumo. Quem seriam elas? Não tínhamos a menor idéia do que encontraríamos, mudando o olhar e deixando-se levar pelas perguntas e questionamentos cotidianos nos jogamos neste universo amplo e surpreendente.

O roteiro de perguntas não abordava somente tatuagem, também abrangia a ideia de gostos em geral, histórias de vida, vivências, aflições e opiniões. Tudo para auxiliar na descoberta do momento significativo na escolha da tatuagem no corpo. E tentar desvendar as cortinas do momento da caneta ronronando na pele a cor, o contorno nossa pergunta: - a que se devia tamanho afeto? Que refletia e estava impresso na linguagem corporal do entrevistado.

Considerando a sociedade em constantes mutações e as conseqüentes identidades pluralizadas, a subjetividade seria peça chave na investigação, apesar do cenário local comum.

Para este trabalho entrevistamos quatro pessoas em Natal/RN, dois homens e duas mulheres. São ao todo uma marca da indústria de bebidas, uma de artes plásticas, duas do cinema. O último entrevistado escolheu o mundo dos games e das histórias em quadrinhos. Como vimos, é possível afirmar que todos buscaram as marcas e as imagens da indústria cultural.

O vídeo "Pela Pele: Technicolor em gotas" é a etapa final de um ano de trabalho captando histórias e memórias de um tempo/espaço. Até que fosse possível a edição e finalização do produto audiovisual, os depoimentos, captados em imagem e som, precisavam ser satisfatórios para elaborar considerações pertinentes a esta velha forma de adornar o corpo com o cenário da nossa cultura.

A largada deste trajeto aconteceu na tarde do dia vinte e dois de setembro de dois mil e nove. O lugar escolhido na cidade do Natal/RN foi o Shopping Orla Sul na livraria Poty Livros. A escolha se deu por ser um lugar tranquilo para poder conversar e com bom volume de circulação de pessoas. Visto que o shopping segundo Bauman 
(2001: 117) é o novo templo onde a imagem se torna realidade "estar dentro" e unificados tanto pelos fins quanto pelos meios, tanto pelos valores que estimam quanto pela lógica de conduta que seguem". E também Barbero (1998: 05-09) identifica os centros comerciais como um lugar de encontros dos dias atuais, como era a praça no passado.

O interesse maior deste trabalho era encontrar um lugar possível e tranquilo onde os entrevistados pudessem estar à vontade. Muitas vezes este lugar de encontro foi a residência dos entrevistados, ou estúdio de TV do Laboratório de Comunicação da UFRN. Pois como disse a psicanalista Miriam Chnaiderman (2009: 10) que sempre produz documentários sobre "histórias de vida" em São Paulo.

Numa entrevista que realizei, uma pessoa disse que na hora em que você está diante da câmera e sabe que isso vai virar documentário (um registro de si mesmo), a fala se torna politizada, porque vai ser pública, então a pessoa vira parte da comunidade. Há uma pertinência ao mundo que se instaura quando você fala para uma câmera.

\title{
2. MEU CORPO: UM PALCO DO QUE “SOU” DESEJO E PENSO
}

\author{
A profundeza, é preciso \\ escondê-la. Onde? Na superfície.
}

Hofmannsthal ${ }^{3}$

Segundo Bougnoux (1999) a comunicação nos novos tempos agrega novas práxis dos olhares. Estamos diante de um mundo em mutação constante e para se sentir pertencentes a este novo mundo precisamos usar o corpo para expor o que de dentro dele pode me traduzir na superfície. A permanência social nos leva para linhas fronteiriças do cotidiano, denotando uma comunicação que reverbera e cria novas relações e sistematiza uma circularidade de reflexões. Meu corpo é um palco do que sinto, gosto e desejo. A comunicação precisa acontecer no pré-verbal e o que possuo na pele motiva eu dizer quem sou, que é fruto da comunicação indicial. Como faz a publicidade, o gestual dos clips musicais e a obra de arte. Como reflete o pesquisador:

\footnotetext{
${ }^{3}$ MAFFESOLI, Michel. A Conquista do Presente. RJ: Ed Rocco, 1984: 49
} 
No começo não era o verbo, mas a carne sensível, extensível, os corpos tocam-se e comunicam-se antes dos espíritos, a rede de uma conversa, por exemplo, provem dessas pontes comportamentais lançadas entre os indivíduos, toda a comunidade é tecida por uma malha indicial, tanto mais eficaz quanto ela permanece, amplamente inconsciente ou primária escondida sob as mensagens ou as articulações secundária da comunicação verbal, codificada e midiatizada. (BOUGNOUX, 1999: 21)

Tomar a decisão de ter uma tatuagem, depois disso, escolher o que tatuar no corpo, faz com que as pessoas busquem suas vivências, as histórias de vida, o tempo e espaço vivido.

Nota-se nesta pesquisa preliminar que o jovem tatuado de Natal está conectado com os jovens tatuados. Numa das entrevistas quando estávamos entrevistando uma das jovens, logo em seguida chegou o tatuador que realizou a tatuagem dela e ao entrevistálo, falava dos outros entrevistados com afinidade e familiarização. Havia, nesta fala, uma comunidade imaginada (tribo) "ah sim eu conheço", "estudamos juntos”, "é meu tatuador", "meu amigo", "foi meu namorado", e outras formas de inclusão da vida social.

É importante compreender as tribos como "comunidades de sobrevivência afetiva" (SODRÉ, 2007) dentro da vida urbana. Norbert Elias (1998) considera que as Tribos Urbanas são grupos de iguais que se organizam em comunidades para garantir sua sobrevivência afetiva durante a passagem para a vida adulta. Já para Maffesoli (1987) fala de uma sociabilidade que se exprime numa sucessão de ambiências, de sentimentos e de emoções.

Inúmeros exemplos da nossa vida cotidiana podem ilustrar a ambiência emocional que emana do desenvolvimento tribal (...) As diversas aparências que exprimem muito bem a uniformidade e a conformidade dos grupos, são como outras tantas pontuações do espetáculo permanente que as megalópoles contemporâneas oferecem. (MAFFESOLI, 2000: 16)

As reflexões de Maffesoli estão voltadas para a multiplicidade do eu e a ambiência comunitária que essa multiplicidade produz, chamada pelo autor de paradigma estético, no sentido que permite vivenciar e sentir, em comum, através do corpo e que se manifesta através da idéia de persona, e que se integra numa variedade de cenas e de situações, que só valem porque são representadas em conjunto.

A manifestação privilegiada da estética: de experimentar junto emoções, participar do mesmo ambiente, comungar dos mesmos valores, perder-se, enfim, numa teatralidade 
geral, permitindo, assim, a todos esses elementos, que fazem a superfície das coisas e das pessoas, fazer sentido (MAFFESOLI, 2000: 163)

\title{
3. TRANSCRIÇÕES: TEMPO E ESPAÇO EM CADA PALAVRA AO SENTIR CADA GOTA NA PELE
}

Na gravação das entrevistas e na captação em vídeo e fotografia, podemos ter uma participação maior entre entrevistado e entrevistador no tempo considerado nulo para a imagem captada em vídeo, mas rico para quem está a observar os detalhes e fronteiras entre captação e o momento da entrevista. Muitas vezes neste momento deixamos o gravador ligado e observamos os comentários e as conversas que a pessoa apresenta do que vai falar, ou vai depor perante a câmera de vídeo. Consideramos este tempo da preparação da luz, tripé e câmera, um tempo rico para a entrevista qualitativa (etnográfica). Assim como nos ensina Eduardo Coutinho, que há um diálogo nos pequenos movimentos "os silêncios, tropeços, ritmos, inflexões, retomadas diferenciadas do discurso. E gestos, franzir de lábios, de sobrancelhas, olhares, respirações, mexer de ombros etc. (LINS, 2004: 110)"

\begin{abstract}
Um diálogo que intensifica na interação com Coutinho e se amplia na relação virtual com o espectador, incluindo também uma série de elementos de comunicação não-verbal. Nos filmes do Coutinho, tão importante quanto a fala dos personagens são as expressões faciais e os movimentos do corpo (...) essa posição contraria uma certa teoria do cinema e também uma idéia do senso comum que definem o documentário como arte feita essencialmente de imagens. Um pensamento estreito que não vê a complexidade da imagem e do som da palavra do outro.
\end{abstract}

Entre os incidentes do momento marcado para a entrevista, há muito tempo entre acertar onde será a entrevista e o que será conversado. A pesquisa indicava sempre o objetivo de encontrar pessoas que podiam nos expressar suas escolhas e contar suas histórias. Não seria importante encontrar pessoas que possuíam sensacionais tatuagens com marcas e produtos culturais na pele, se não desejavam contar suas histórias de vida ou, que não tivessem a capacidade de narrar suas escolhas. A transcrição de tudo o que foi dito entre o espaço gravação e a gravação é que permitiu a análise destas entrevistas que escolhemos para este trabalho.

Em seu livro "As palavras e as coisas Foucault” (1967: 477) estabelece uma leitura das mudanças ocorridas do século XIX ao século XX. Diz que o ser humano já 
não tem história, pois quando fala, trabalha e estabelece relações sociais se envolve e se mistura com as histórias que não lhe são subordinadas e nem homogêneas. E afirma que o homem desde o início do século XIX é um ser "desistoricizado" (sem uma história).

A partir deste pensamento podemos buscar a definição de identidade em Hall (2001: 38-39) que diz:

\begin{abstract}
Há um descentramento da identidade nos novos tempos, a identidade é realmente algo formado, ao longo do tempo, através de processos inconscientes, e não algo inato, existente na consciência no momento do nascimento. Existe sempre algo "imaginário" ou fantasiado sobre sua unidade. Ela permanece sempre incompleta, está sempre "em processo", sempre "sendo formada"(....) Em vez de falarmos da identidade como uma coisa acabada, deveríamos falar de identificação, e vê-la como um processo em andamento. A identidade surge não tanto da plenitude da identidade que já está dentro de nós como indivíduos, mas de uma falta de inteireza que é "preenchida" a partir de nosso exterior, pelas formas através das quais nós imaginamos ser vistos por outros. Psicanaliticamente, nós continuamos buscando a "identidade" e construindo biografias que tecem as diferentes partes de nossos eus divididos numa unidade porque procuramos recapturar esse prazer fantasiado da plenitude.
\end{abstract}

Dentro desta lógica vamos descrever e analisar as cinco tatuagens de marcas e produtos culturais na pele de quatro entrevistados. Tentamos traduzir em uma palavra cada depoimento transcrito e o que a tatuagem representava em seus corpos, e chegamos às seguintes palavras:

\begin{tabular}{|l|l|l|l|}
\hline Iniciais do nome & Sexo/idade/profissão & Tatoo e Onde & Palavra e Tatoo \\
\hline C.T. & $\begin{array}{l}\text { Feminino, 22 anos, } \\
\text { videomaker }\end{array}$ & $\begin{array}{l}\text { Alex (personagem } \\
\text { principal de } \\
\text { Laranja Mecânica) } \\
\text { na coxa direita }\end{array}$ & AUTOANÁLISE \\
\hline L.F. & $\begin{array}{l}\text { Feminino, 24 anos, } \\
\text { publicitária }\end{array}$ & $\begin{array}{l}\text { Marca do Jack } \\
\text { Daniels (wisky), } \\
\text { nas costas }\end{array}$ & RESPEITO \\
\hline R. P. & $\begin{array}{l}\text { Masculino, 29 anos, } \\
\text { tatuador }\end{array}$ & $\begin{array}{l}\text { Salvador Dali e } \\
\text { Jack Nicholson, na } \\
\text { perna no braço }\end{array}$ & EXPRESSÃO \\
\hline M.G.A.N. & $\begin{array}{l}\text { Masculino, 27 anos, } \\
\text { ator e barman }\end{array}$ & $\begin{array}{l}\text { Night Elf do jogo } \\
\text { virtual War of } \\
\text { Craft, a tatuagem } \\
\text { está nas costas toda }\end{array}$ & PROTEÇÃO \\
\hline
\end{tabular}

C.T. radialista, com 22 anos, escolheu para tatuar a imagem de Alex (o sem lei), personagem de Laranja Mecânica, exatamente a cena do momento que estão fazendo a 
lavagem cerebral e mostrando suas ações no tempo. Os olhos estão presos por pinças e um colírio ajuda a umedecer os olhos durante a ação. Esta é a imagem que. C. T. escolheu, sempre trabalhou com produção de audiovisual, nasceu e morou em Natal toda sua vida. Quando assistiu ao filme "Laranja Mecânica", ainda com 16 anos, ficou atenta a cena da lavagem cerebral com o personagem Alex dentro da narrativa do filme. E cada vez que ela assistia, conforme ia amadurecendo, a cena ganhava novas interpretações.

Além de assistir ao filme C. T. comprou o livro e releu muitas vezes. Disse que quando leu começou a criar e imaginar outras imagens da mesma cena. Segundo ela, “era tão desafiador a descrição da cena que era como se enxergássemos nós mesmo a partir da lavagem cerebral ocorrida tanto no filme quanto no livro”.

Esta cena eu usava como quadro assim no meu quarto, eu a imprimi. Até que um dia eu descobri que uma pessoa tinha tatuado um 'Salvador Dali' na perna. Era um realismo perfeito. (...) e a pessoa me disse com quem havia tatuado. Eu fui atrás, quando eu tinha uns dezoito anos... Como era muito caro, eu deixava pra depois, pra depois, pra depois. Até que um dia houve a proposta de fazer esse trabalho e levar pra uma convenção de tatuagem, que aí foi quando barateou e eu pude fazer a tatuagem. ${ }^{4}$

C. T. nos mostra que gosta da tatuagem e que se identifica com ela profundamente. Diferentemente da interpretação ou julgamento das tatuagens no senso comum (narrado por muitos dos entrevistados) dizendo que quem se tatua não pensa e não tem pré-julgamentos. A tatuagem de C.T. foi elaborada no tempo. Esperou, pensou, foi atrás, desde o dezesseis anos e tatuou aos 21 anos. Para realizar a tatuagem exatamente como imaginou e idealizou, teve que ir muitas vezes ao tatuador. Uma verdadeira obra de arte na coxa direita.

O informante nos diz que considera que esta imagem tem muito do que ela pensa e viveu e vai viver ainda em sua vida. A tatuagem que foi realizada na coxa da perna direita é uma imagem representativa de C.T. e muito importante para ela. Foi algo decidido no tempo e na própria experiência de vida de C. T. Como nos mostra também no depoimento abaixo:

\footnotetext{
${ }^{4}$ Depoimento captado no café da Poty Livros do Shopping Orla Sul em Natal/RN dia 22/09/2009.
} 
As pessoas se desesperam quando olham o que fazem. É mais ou menos essa minha interpretação... É porque, não só a tatuagem, não é que eu olho pra tatuagem e fico lembrando disso ...eu vou ficar, vou criar um lembrete para mim, tenho que sempre ficar olhando minhas ações. (...) Essa reavaliação do que você faz eu quis perpetuar, até porque a cena mesmo é forte, a fotografia é forte e como eu sou uma pessoa muito visual, a imagem ficou marcada. (...) aí eu disse: -vou marcar isso no meu corpo (...) A gente deveria ser obrigado, por nós mesmos, todos os dias a parar um pouquinho e pensar assim o que vocêfez. Acho que são as oportunidades das nossas ações.

C. T. diz que a identificação com as tatuagens nasceu desde os 11 anos de idade, primeiro pelos estilos das músicas que gosta e depois pelas bandas que sempre gostou nelas as pessoas geralmente estavam tatuadas. Desta forma a tatuagem virou algo familiar para C.T. "todo o tempo vemos pessoas tatuadas, isso é normal hoje em dia". Para ela a tatuagem é como uma vestimenta que você cria e usa para sempre: "Eu fíco às vezes viajando se todo mundo fosse todo tatuado, cada um ia ter identificação de vida assim no seu corpo. Suas crenças, e tudo... seria tipo uma roupa que você vai escolhendo vestir pra sempre".

Uma imagem que traz proteção para M.G.A.N. 27 anos ator e barman, é Night Elf do jogo War of Craft, uma imagem que realizou nas suas costas inteiras e precisou de uma no de trabalho. M.G.A.N. tem tatuagens no corpo todo, imagens de elfos, caveiras e do mundo mitológico. Cada tatuagem representa as fases de sua vida e seus gostos e paixões. Ele é potiguar, é casado, e sua esposa acompanhou a entrevista que aconteceu em sua residência e foi a que mais durou, uma hora e meia de conversa.

Segundo M.G.A.N, "Night Elf” é um devorador de demônios, que incorpora a forma dos monstros que come, então sua aparência é uma constante mutação. "War of Craft” é um jogo virtual que evoluiu do RPG e tem outros produtos correlacionados, como gibis que ensinam truques para ultrapassar etapas.

O "Night Elf” para M.G.A.N. representa proteção contra inveja e olho grande. Não o assusta o fato de se tratar de um demônio, pois para ele é um demônio do bem. A maioria de suas tatuagens "é forte", mas como ele mesmo diz: "eu acho que questão de estilo, eu acho que me ajuda a dizer o como eu sou, a forma que eu sou, apesar que minhas tatuagens são agressivas e eu não sou nem um pouco". Tatuar é um vício como nos fala:

Eu criei uma compulsão, eu achava pouco, ia pras convenções e achava todo mundo muito irado, todo mundo com bastante tatuagem e eu só com aquela do braço, coisa bem discreta, então eu comecei a fazer a da perna, levei um ano pra fazer ela, depois 
fiz o outro braço, as duas ao mesmo tempo e agora eu tô terminando a das costas, minha idéia é tentar fechar o corpo, não do pescoço pra cima, só do pescoço pra baixo, porque minha idéia é vender a própria pele depois, pra ficar exposta, pras pessoas saberem como é o fato de você ter uma tatuagem no corpo, como é prazeroso".

M.G.A.N. é desenvolto, solícito, cativante e valoriza muito a arte. A "body art" faz parte de sua essência e a tatuagem do "Night Elf", como as demais, lhe traz proteção:

Quem não me conhece, me vê, olha aquele cara ali parece um marginal, sei lá, pode ser uma pessoa ruim, e é uma proteção pra mim, as tatuagens chegam a ser uma proteção porque eu me torno uma pessoa. Eu sou uma pessoa tímida, né, então eu me torno uma pessoa recuada, então elas não me incomodam e eu não incomodo elas.

Muitas vezes durante a entrevista M.G.A.N. cita a família, a sociedade como responsáveis pelo olhar preconceituoso em relação a suas tatuagens. O entrevistado acha que o preconceito tem que acabar e quando indagado sobre a sociedade, alegou que as pessoas precisam ter mais amor.

JACK DANIELS e L.F. (24 anos, publicitária) uma relação de respeito. L. F. foi entrevistada no estúdio de laboratório de comunicação da UFRN, no dia vinte e dois de outubro de 2009. Muito ocupada, veio direto do serviço, trabalha com arte-finalista e tem várias tatuagens.

Uma mulher moderna, assumidamente boêmia, que valoriza a independência e traz o lado aventureiro da infância, que foi repleta de viagens, acampamentos e visita a estande de tiros.

Desenrolada, fala do medo da violência e aponta os jovens do esporte com um maior destaque. L.F. faz diferentes tipos de lutas e é muito ativa. Entre tantas tatuagens, talvez a mais exótica seja a da sua nuca até as costas, a marca do whisky "Jack Daniel's".

A logomarca pode ser considerada um produto visual de grande alcance, vide os pertences da entrevistada:

Eu descobri que existe toda uma indústria atrás da marca, de produtos licenciados, então eu tenho fivelas de cinto, eu tenho até um quadradinho de giz de sinuca, que você coloca no taco de sinuca que é do Jack Daniel's., todos os meus amigos que viajam pra

\footnotetext{
${ }^{5}$ Entrevista realizada em 02/01/2010 na residência do entrevistado em Natal/RN.
} 
algum lugar que acham alguma coisa do Jack Daniel's trazem pra mim, eu tenho bandanas, eu tenho copos, tenho garrafas, eu tenho garrafas de todos os tamanhos, de um litro e meio, de setecentos, garrafinha pequeninha, tenho miniatura, enfim, brochinhos, tudo que você imagina do Jack Daniel's

Apaixonada por música e leitura e aficionada por desenhar, adquiriu uma lesão na mão no trabalho com tratamento de fotos, fato que a impediu de seguir, no entanto desviou a vontade de colocar o desenho pra si.

O interesse pelo whisky Jack's Daniels "simboliza mais que um gosto, marca também a época de sua vida", que como bartender, conheceu melhor a história da bebida. O desenho em especial a agrada: "a logomarca em si, além de ela ser muito bonita do ponto de vista do design, eu não sei... eu me identifiquei com ela, por ser uma coisa meio forte e eu gosto de ter esse lado feminino forte comigo". No entanto, a mensagem se estende:

\begin{abstract}
As vezes eu chego num bar, assim um cara super velho, mal encarado me olha com a cara meio feia... Ah, mulher tatuada, não sei o que... eu chamo o garçom e digo: - por favor um Jack Daniel's! Ele já me olha: nossa, mas você bebe Jack Daniel's, engraçado uma mulher beber Jack Daniel's, aí eu falo: - nossa eu gosto muito, eu tenho uma tatuagem do Jack Daniel's. Então eles já me vêem como outros olhos, eu acho que isso demonstra que eu tenho respeito por eles, eu acho que é isso, Jack's Daniel's me lembra respeito, me lembra uma coisa antiga, forte e me traz respeito.
\end{abstract}

Ela evidencia na entrevista se sentir incomodada com os olhares preconceituosos: "eu odeio ir pra lugares assim que não são da minha, do meu, da minha panelinha, digamos assim, por exemplo, odeio ir pra fila de banco, odeio ir pra consultório médico porque sempre tem uma velhinha do meu lado", e é como se a tatuagem do whisky resgatasse parte do devido respeito.

Suas tatuagens dialogam por si próprias:

Eu acho que é liberdade, independência e meio que eu gosto de colocar isso, acho que assim: nasci pra ser selvagem, nasci pra... Acho que cada uma tem um pedacinho dessa história de mim, se você juntar todas as coisas, você monta uma L.F.

SALVADOR DALI E JACK NICHOLSON neste mesmo dia R.P. deu seu depoimento às oito horas da noite, ao sair do seu trabalho. R.P é tatuador, 29 anos, nasceu no Amazonas e se mudou para Natal há vinte anos, se considera potiguar. Formado em criação e desenvolvimento de websites e especializado em carcinicultura 
sustentável, teve de vencer o preconceito interno para se dedicar unicamente ao seu ofício de tatuador.

R.P. vive um momento especial, seu primeiro filho está para nascer e este fato lhe despertou preocupações com o futuro. O entrevistado de muitas tatuagens tem em sua perna esquerda dois grandes representantes da arte. Salvador Dali, sua inspiração em pinturas de telas, com destaque para o peculiar surrealismo do artista, e Jack Nicholson, do cinema, dado a enorme expressividade do ator.

Pelas palavras do entrevistado:

Bom, eu particularmente me identifico muito com as expressões faciais dele, sabe, porque eu acho que Jack Nicholson só ele tem aquelas expressões e assim pra quem trabalha com cinema e arte cênica, isso é, expressão é praticamente tudo e eu acho que Jack Nicholson é uma referência de expressões.

A foto de Jack Nicholson foi tirada de uma capa de revista. Não é a imagem tradicional que normalmente relacionamos ao pensar em Jack Nicholson, que tem hoje mais de setenta anos, consagrado em sua filmografia. Na figura ele ainda é moço, no início da sua carreira e tem um cigarro na boca, mas é indiscutível o fácil reconhecimento.

Quando alguém pergunta quem é na tatuagem, R.P. se indigna e se de mau humor, até responde que é seu pai:

Então assim por ser uma referência no cinema eu ainda encontro pessoas que sequer reconhecem o cara, sabe, eu fico me perguntando: pô, como assim, que mundo você tá de não saber quem é Jack Nicholson, saca?

As tatuagens de R.P. são uma homenagem as suas referências de identificação na arte, que definem muito de sua identidade.

\section{CONSIDERAÇÕES FINAIS}

Embora o roteiro de perguntas aplicado tenha sido o mesmo, cada entrevista apresentou uma aura singular, dado as inúmeras variáveis e reverberações da comunicação instaurada. No entanto, o que os unia era o fato de terem uma tatuagem de um produto de consumo. 
Nas questões que não tangiam a vida particular, alguns pontos podem ser observados. Ao serem questionados, o que lhes chocava na sociedade atual, os entrevistados responderam a violência, o aquecimento global e os problemas de desgaste e pouco caso com a natureza. E também a intransigência com as mudanças e a falta de amor.

$\mathrm{Na}$ suposição de que se tivessem o poder de mudar algo, o que o fariam, disseram que usariam o tempo de uma forma mais crítica e criativa. E quando perguntamos se achavam que havia alguma chance de se arrependerem da tatuagem, todos responderam que não. Mas frisamos que dois responderam a arte do cover-up, e dois deles já usaram a arte para cobrir algo que não representavam mais nada em sua vida, ou seja, cobriram uma tatuagem por outra.

L. F. e MG.A.N. tem em comum o gosto por lutas marciais, o fato de terem sido bartender e o notável incômodo com o preconceito. Na hora da escolha decidiram optar por uma tatuagem que representasse a si mesmo, no sentido de autoproteção e autoanálise.

Assim como C.T. e R.P. a tatuagem é como uma interpretação daquilo que são e escolheram para identificar sua vida e expressão.

Como nos afirma uma pesquisa realizada em São Paulo e Natal sobre a representação dos jovens nas capitais das pesquisadoras Costa e Rocha (2007).

O corpo é em si a sede e meio de comunicação. É a mídia primária, o meio primordial de contato com o mundo de que os seres humanos se utilizam (...). As sociedades ocidentais capitalistas valorizam sobre maneira as palavras como meio de expressão, mas elas são substitutas pobres das sensações complexas experimentadas intimamente. Daí, a recorrência a artifícios para a expressão na pele e sobre a pele: pinturas corporais, tatuagens e roupas. ${ }^{6}$

A história da tatuagem de cada entrevistado está diretamente relacionada com suas experiências de vida, que mesmo numa cidade comum, são diferenciadas no contexto, assimilação e significação.

A comunicação corporal da tatuagem é abrangente, pois se refere não apenas a um sinal, e sim a um novo estilo de vida adotado. A expressão da tatuagem só pode ser

\footnotetext{
${ }^{6}$ http://www.compos.org.br/files/18ecompos09_Rose_Josimey.pdf: 13-14
} 
interpretada mediante seu sujeito, que carrega demais características convergentes ou não.

Mesmo que não propositalmente, houve nos casos citados, a conversão da mídia audiovisual para uma mídia alternativa, pois a tatuagem incide em um outdoor ambulante, que divulga e comunica. A vida é midiática e é vivida no cotidiano, onde a intimidade e as escolhas estão presentes.

\section{REFERÊNCIAS BIBLIOGRÁFICAS}

APPADUAI, Arjun. Dimensões Culturais da Globalização. Lisboa: Teorema. 2004.

BAUMAN, Zigmunt. Modernidade Liquida. RJ: Jorge Zahar, 2001

BARBERO, Martin. Comunicação e Cidade: entre meios e medos. Revista Novos Olhares- Grupo de Estudos sobre práticas de recepção a produtos midiáticos, SP ECA/USP, ano 01, nº 1, 1998

BOUGNOUX, Daniel. Introdução às ciências da Comunicação. Bauru: EDUSC, 1999

CHNAIDERMAN, Miriam. Travessias. Revista Ocas: saindo das ruas $\mathrm{n}^{\mathbf{0}} 66$ julho/agosto, 2009

CANEVACCI, Massimo. Culturas eXtremas, mutações juvenis nos copos das metrópoles. Rio de Janeiro: DP\& A, 2005.

A comunicação entre corpos e metrópoles. P.01 - 15. http://www.usp.br/signosdoconsumo/artigos/artigo01_comunicacao_entre_corpo s_metropoles.pdf

FEATHERSTONE, Mike (org). Body Modification. London: Sage Publication Ltd, 2005.

FOUCAULT, Michel. As palavras e as coisas. Lisboa: Portugália Editora, 1967

HALL, Stuart. A identidade na pós-modernidade. Rio de Janeiro: DP\&A Editora, 2001

LE BRETON, David. As Paixões Ordinárias: Antropologia das emoções. Petrópolis RJ: Vozes, 2009.

LINS, Consuelo. O documentário de Eduardo Coutinho: TV, cinema e vídeo. RJ: Ed. Zahar, 2004

MAFFESOLI, Michel. O tempo das Tribos: declínio do individualismo nas sociedades de massa. RJ: Forense, 2000. 
- A Conquista do Presente. Rio de Janeiro: Ed. Rocco. 1984

PAVAN, Maria Angela, TRINDADE, Eneus Memória da pele e histórias do consumo: marcas e produtos tatuados no corpo. In: MACHADO, Maria Berenice (Org.). Publicidade e Propaganda: 200 anos de história no Brasil. Novo Hamburgo: Ed. Feevale, 2009

QUEIROZ, Maria Isaura Pereira de. Variações sobre a técnica de gravação no registro da informação viva. SP: T.A. Queiroz, 1991.

ROCHA, Rose de M.; SILVA, Josimey C. da. Consumo, cenários comunicacionais e subjetividades juvenis. In: E-Compós $\mathrm{n}^{\circ}$ 09, agosto de 2007. Revista da Associação Nacional dos Programas de Pós-Graduação em Comunicação.

Disponível em: http://www.compos.org.br/files/18ecompos09_Rose_Josimey.pdf , p- 13-14.

SODRÉ, Muniz. As estratégias sensíveis: afeto, mídia e política. Petrópolis: Vozes. 2006.

SOUZA, Mauro Wilton. Recepção midiática: linguagem de pertencimento. Revista Latinoamericana de Ciencias de la comunicación. São Paulo: ALAIC. jan-jun. 2, 2005

Artigo submetido: agosto de 2012

Artigo aprovado: outubro de 2012 